\title{
Clinical Cold-Welding of the Modular Total Hip Arthroplasty Prosthesis
}

Article · August 2016

DOI: $10.1016 /$ j.arth.2016.07.020

CITATION

1

6 authors, including:

Robert Whittaker

University College London

18 PUBLICATIONS 31 CITATIONS

SEE PROFILE

John A Skinner

University College London

261 PUBLICATIONS 4,744 CITATIONS

SEE PROFILE
Harry Hothi

WWW.LIRC.co.uk

28 PUBLICATIONS 45 CITATIONS

SEE PROFILE

\section{Alister J Hart}

University College London

148 PUBLICATIONS $\quad 2,269$ CITATIONS

SEE PROFILE

Some of the authors of this publication are also working on these related projects:

Project Taper corrosion of hip implants View project

Project Taper corrosion of hip implants View project 


\section{Accepted Manuscript}

Clinical Cold-Welding of the Modular Total Hip Arthroplasty Prosthesis

Robert K. Whittaker, Ahmed Zaghloul, Harry S. Hothi, Imran A. Siddiqui, John A.

Skinner, Alister J. Hart

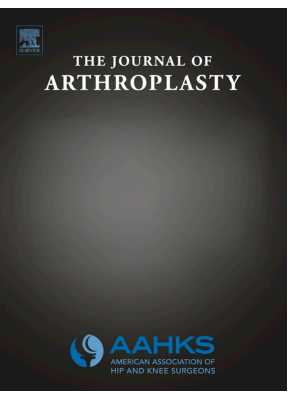

PII:

S0883-5403(16)30442-9

DOI:

10.1016/j.arth.2016.07.020

Reference: YARTH 55319

To appear in: The Journal of Arthroplasty

Received Date: 12 August 2015

Revised Date: 27 June 2016

Accepted Date: 21 July 2016

Please cite this article as: Whittaker RK, Zaghloul A, Hothi HS, Siddiqui IA, Skinner JA, Hart AJ, Clinical Cold-Welding of the Modular Total Hip Arthroplasty Prosthesis, The Journal of Arthroplasty (2016), doi: 10.1016/j.arth.2016.07.020.

This is a PDF file of an unedited manuscript that has been accepted for publication. As a service to our customers we are providing this early version of the manuscript. The manuscript will undergo copyediting, typesetting, and review of the resulting proof before it is published in its final form. Please note that during the production process errors may be discovered which could affect the content, and all legal disclaimers that apply to the journal pertain. 


\section{TITLE PAGE}

Title: Clinical Cold-Welding of the Modular Total Hip Arthroplasty Prosthesis

Authors: Robert K. Whittaker ${ }^{1}$, Ahmed Zaghloul ${ }^{1}$, Harry S. Hothi ${ }^{1}$, Imran A. Siddiqui ${ }^{1}$, John A. Skinner ${ }^{1}$, Alister J. Hart ${ }^{1}$

Institute of Orthopaedics and Musculoskeletal Science, University College London and the Royal National Orthopaedic Hospital, Stanmore, United Kingdom

Corresponding Author: Robert K. Whittaker

${ }^{1}$ Institute of Orthopaedics and Musculoskeletal Science (University College London) Royal National Orthopaedic Hospital

${ }^{2}$ Institute of Biomedical Engineering (University College London)

Royal National Orthopaedic Hospital

Brockley Hill

Stanmore, London

HA7 4LP

United Kingdom

Phone: +44 (0) 2089095825

Fax: +44 (0) 2089548560

Email: r.whittaker@ucl.ac.uk 
1 Title: Clinical Cold-Welding of the Modular Total Hip Arthroplasty Prosthesis

2

3

4

5

6

7

8

9

10

11

12

13

14

15

16

17

18

19

20

21

22

23

24

25 
Abstract

Background - A head that is 'clinically cold-welded' to a stem is one of the commonest reasons for unplanned removal of the stem. It is not clear which hip designs are at greatest risk of clinical cold-welding.

Methods - This was a case-control study of consecutively received hip implant retrievals; we chose the design of hip that had the greatest number of truly coldwelded heads $(n=11)$. For our controls we chose retrieved hips of the same design but without cold-welding of the head $(n=35)$. We compared the clinical variables between these two groups using nonparametric Mann-Whitney tests to investigate the significance of differences between the cold-welded and non-cold-welded groups.

Results - The design that most commonly caused cold-welding was a combination of 
Introduction

51

Modular hip replacement systems are commonly used during primary total hip replacement (THR) surgery, with approximately 70,000 modular hips implanted annually in the United Kingdom [1]. The additional interface found between the head and neck or the stem and sleeve adaptor allows for variable reconstruction of the implant. During primary surgery, this affords the surgeon greater flexibility to adjust the femoral head size, offset and leg length [2-4]. Furthermore, the ability to retain a well fixed femoral stem simplifies revision surgery as only the head in this instance would require exchange [5]. The head-neck interface however has also been shown to be subject to corrosive processes and fretting that can lead to premature implant failure [6].

When the modular hip cannot be separated during revision surgery, this is referred to as 'clinical cold-welding'. As a consequence, the inseparable implant must be removed, often requiring specialised instruments, osteotomy and a new stem with diaphyseal fixation. Alternatively, the femoral head may be sectioned to remove it from the stem trunnion however this approach has a limited margin for error. With a large at-risk population, surgeons should be aware of the possibility of a clinically cold welded head when planning revision surgery, to ensure the appropriate equipment is available for the procedure.

Several retrieval studies have reported this phenomenon in the literature [7-11] however no study has directly investigated the extent to which cold welding is prevalent within the population or the risk factors which may lead to the formation of this inseparable interface. Our aim was to investigate the factors that influence the 
73 formation of a clinical cold weld, to better understand its clinical significance and guide surgeons during revision surgery.

To achieve this, we defined the following objectives: (1) determine the effectiveness of current intraoperative equipment at separating the head from the stem, determine the force required to mechanically disassemble the head from the stem in cases that could not be separated using intraoperative equipment, (3) correlate the difficulty of head-neck separation with clinical and implant factors using a control group of non- cold welded hips to ascertain if the presence of a clinical cold weld can be predicted preoperatively.

\section{Patients and Methods}

This was a retrieval study of a consecutive series of implants at our tertiary retrieval centre. Figure 1 provides a summary of the study design.

\section{Demographics (Table 1)}

Between 2007-2015, a total of 600 metal-on-metal (MOM) failed total hip replacement (THR) prostheses were received at our centre. These consisted of 440 THR bearing couples that were received without a femoral stem and 180 bearing couples with a femoral stem. Of the 180 received with a femoral stem, 27 had the femoral head retained on the femoral stem such that the implant appeared to be clinically cold-welded (CCW).

The 27 bearings that appeared to be CCW consisted of Biomet M2a-Magnum (Warsaw, Indiana) paired with a Taperloc or Bi-Metric femoral stem $(n=13)$, Pinnacle (DePuy, Warsaw, Indiana) paired with a Corail $(n=2)$, ASR (DePuy, Warsaw, Indiana) paired with a Corail $(n=4)$ Mitch Exeter (Kalamazoo, Michigan, United States) $(n=2)$. 
The Biomet M2a-Mangnum are such that the stems (Taperloc and Bi-Metric) and the taper sleeve are both $\mathrm{Ti}$ with $\mathrm{CoCr}$ bearings; all other head-stem junctions had a cobalt-chromium-titanium (CoCr-Ti) or cobalt-chromium-stainless steel (CoCr-SS) material combination with either monoblock $\mathrm{CoCr}$ head or a $\mathrm{CoCr}$ head with a $\mathrm{CoCr}$ taper sleeve (Table 2).

These implants were retrieved from 13 male and 14 female patients with a median age of 58 years (48-78) and a median time to revision of 53 months (25-131). The median head size of the implants was $46 \mathrm{~mm}(28-58)$.

\section{Disassembly Test: Head-neck separator}

We obtained 5 commercially available femoral head-neck separators that are commonly used at our institution intraoperatively to attempt disassembly of the headneck junction; these were manufactured by JRI, Stryker, Biomet and Smith \& Nephew. Each implant that we suspected as being clinically cold welded was individually secured to a laboratory bench with a clamp. Disassembly of the head from the stem was then attempted by two experienced orthopaedic surgeons using the 5 head-neck separators; both surgeons were informed to limit the force applied to the separators to that which they would expect to apply intraoperatively. In this study we considered an implant to be truly clinically cold welded if the head-neck junction could not be separated by any of the 5 devices. The JRI head-neck separator is shown in figure 2.

\section{Disassembly Test: Mechanical testing system}

For this test we used the Ti-Ti pairing of the Biomet M2a-Magnum with the Biomet Type 1 Taper; this combination was discovered to have the highest prevalence of cold welding from our head-neck separator tests. We then selected a single implant 
120 at random that was found to be clinically inseparable and performed a mechanical

121 disassembly test using a Proline (Zwick Roell) testing machine To secure the implant

122 for the test, we clamped the femoral head to the base of the machine and fixed the

123 shaft of the stem to the opposing end of the machine using polymethylmethacrylate

124 (PMMA) bone cement. A controlled tensile test at a speed of $1 \mathrm{~mm} / \mathrm{min}$ was

125 performed to determine the force at which disassembly would occur; the test was to

126 be ended if separation of head and stem occurred or if the limit of the testing device

127 (5000 Newtons) was reached.

\section{Corrosion Surface Assessment}

129 We obtained informed consent to section a cold-welded Biomet M2a-

130 Magnum/Taperloc hip along the Ti sleeve adapter in order to reveal the engaged surfaces of the taper and trunnion. A single examiner experienced in retrieval analysis used macroscopic and light microscopy to determine the severity of corrosion of both engaging surfaces using the scoring system (scale 1 to 4) developed by Goldberg and colleagues [12]. Using the same criteria, we also corrosion scored the head and trunnion of the implants that were successfully disengaged by the head-neck separators.

\section{Selection of Control Group}

To ascertain if any factor could be used to determine if cold welding had taken place pre-operatively we chose the design of hip that had the greatest number of truly cold welded heads (Biomet M2a-Magnum, $n=11$ ). We then chose retrieved hips of the same design that had not cold welded $(n=35)$. We used a non-parametric Mann- 
and non cold welded groups in relation to (1) time to revision, (2) head size, (3) patient age at primary surgery, and (4) gender.

\section{Results}

Of the 600 failed THRs received at our centre, $4.50 \%$ were received with the femoral

147 head retained on the femoral stem such that the implant appeared to be clinically 148 cold-welded.

\section{Disassembly Test: Head-neck separator}

We found that the head could be separated from the stem using the head-neck separators in 11 cases (Table 3 ); this revealed that 16 implants received at our centre were truly clinically cold-welded. These were the M2a-Magnum/Type 1 Taper $(n=11)$, ASR XL/Corail $(n=2)$, Cormet/Zweymuller $(n=2)$ and Mitch/Exeter $(n=1)$

\section{4 (Table 4).}

We noted that the JRI model head-neck separator removed the head most frequently when the four others had failed. This model successfully separated 10 of the 11 that we managed to disengage.

We noted that the Ti-Ti M2a-Magnum/Type 1 Taper had the highest prevalence of clinically cold welding of the implants that we received at our centre. This implant design was used for our mechanical disassembly test.

\section{Disassembly Test: Mechanical testing system}

162 Figure 3 represents the stress-strain graph produced from our disassembly test. We 163 found that the M2a-Magnum/Taperloc Ti-Ti taper junction could not be separated 
even after reaching the maximum separation force of 5000 Newtons of the testing system.

\section{Corrosion Surface Assessment}

Examination of the engaged surfaces following sectioning of the taper adapter revealed evidence of severe corrosion on both the head taper and stem trunnion; these were graded as 4 according to Goldberg's classification system. The length of engagement of the two surfaces was measured as $18 \mathrm{~mm}$.

Figure 4 shows in detail the $\mathrm{Ti}$ corrosion of the M2A-Magnum sleeve and stem trunnion. The original surface of both the taper sleeve and the trunnion have corroded to deviate from the 'as manufactured' profile.

All heads and trunnions that could be disengaged with the head-neck separator showed evidence of mild to severe corrosion. The heads had a median corrosion score of 4 (2-4) and the trunnions had a median corrosion score of $3(2-4)$.

\section{Comparison of cases and controls}

The design that most commonly caused cold welding was a combination of a Ti stem and $\mathrm{Ti}$ taper: 11 out of $48 \mathrm{Ti}-\mathrm{Ti}$ interfaces received at the retrieval centre between 2007-2015 (23\%) were truly cold welded after use of 5 head/stem separators. Comparison of the clinical data from the cold welded group to the non cold-welded group with $\mathrm{Ti}-\mathrm{Ti}$ interfaces showed no individual factor could be used to predict this preoperatively as none of the 4 predictors tested showed any significance (1) time to revision ( $(=0.687)$, (2) head size $(p=0.067)$, (3) patient age at primary $(p=0.380)$, (4) gender $(p=0.054)$ (Table 5). 


\section{Discussion}

We have presented evidence of clinical cold welding of retrieved THRs received at our centre in which the femoral head was inseparable from the femoral stem intraoperatively. We report a prevalence of $4.5 \%$ at our centre.

There is little clinical or retrieval evidence to indicate the scale of the problem of cold welding of the head and stem. Mokka et al. reported 2 cases in which a Biomet M2aMagnum head could not be detached from its corresponding stem (Ti-Ti junction); this was attributed to extensive corrosion at the engaging interface [11]. Furthermore, two Australian studies found $22 \%$ and $27 \%$ of cases were clinically cold welded. The figure we reported is likely to underestimate the true population prevalence due to inherent collection bias however we used a broad inclusion criteria to minimise this effect.

A number of studies have reported evidence of CCW of the titanium modular neck and stem [7-9] in which all the retrieved components showed signs of severe frettingcorrosion. Kop et al. demonstrated that severe corrosion can occur at the modular junctions of THRs regardless of the material of stem and taper, however noted that cold welding only occurred in titanium based junctions [9].

We attempted disassembly of the components in our laboratory to ascertain the number of truly inseparable implants using all current intraoperative equipment. After the use of the 5 commercially available head-neck separators, we discovered that 16 implants could still not be separated. Therefore, of the implants that appeared clinically cold welded at retrieval, approximately $40 \%$ were able to be separated using the correct equipment. We found the JRI separator was superior as this model was able to successfully remove the head when the 4 others had failed. 
211 The most frequent cold-welded design was that of the Biomet M2a-Magnum head and Type 1 Taper stems; this was the only design with a Ti-Ti taper junction. Further testing of this implant design using our mechanical disassembly machine was also unable to separate the head from the stem, despite reaching a maximum separation force. Clinical cold-welding is therefore most prevalent in $\mathrm{Ti}-\mathrm{Ti}$ combinations of this stem and taper in our study, with approximately $25 \%$ of cases cold-welded.

A Ti-Ti junction is an indicator that a clinical cold-weld maybe present at revision surgery. The mechanism that facilitates the Ti-Ti junctions becoming cold welded appears to be caused by the corrosion of the Ti causing the material in the junction to decrease in density and therefore increase in volume preventing it from becoming disengaged due to an increase in the sheer force needed to overcome the friction as shown in figure 4. A reason this may not be seen in CoCr-Ti head-stem combinations is that the corrosive processes that take place with these material combinations includes galvanic corrosion, with the $\mathrm{CoCr}$ head corroding preferentially to the $\mathrm{Ti}$ stem due to the more stable oxide film on the Ti when paired with $\mathrm{CoCr}$. This mechanism has been shown in a number of retrieval studies and is exemplified by the imprinting of the Ti stems machined groves on the head taper [6, 13-17].

We correlated the difficulty of head-neck separation with clinical and implant factors using a control group of non cold-welded hips to ascertain if cold-welding could be predicted preoperatively. Analysis of these clinical variables showed that it is currently not possible to predict which implants will be cold welded preoperatively using these factors alone with an example of this shown in figure 5, however, we were unable to assess the power needed so the lack of a relationship may be due to the numbers used in the study. A larger data set may show one of these variables to be significant in the future. 
Surgeons should be aware of the potential risk of a cold welded implant prior to revision surgery. The presence of a cold weld can significantly increase operation time and may increase patient morbidity as often, a more complicated procedure is required. With all the correct equipment available, at least one hour of operation time is added for the trochanteric osteotomy with cables +/- plating and the use of a more complicated femoral stem [18]. If the equipment is unavailable then the procedure can take multiple extra hours or the surgery must be abandoned, as has happened in our experience. This, furthermore, may increase the length of in-patient stay or recovery time and the risk of future complications in patients [19]

In our study, although surgeons were instructed to apply a force no greater than that used during surgery while testing the head neck separates, we acknowledge that our investigation may not fully simulate the intraoperative environment. Furthermore, a large multicentre analysis of cold welding is required to reveal whether patient factors can be used to predict the formation of a cold-weld. It was only possible to section one implant and we can therefore only have extrapolated that all similar inseparable implants have undergone a similar processes of corrosion.

Our study was the first to directly investigate prevalence and risk factors of clinical cold-welding within the population. Clinical cold welding was found in $4.5 \%$ of retrieval implants. Using the appropriate equipment, we found that cold welding was truly present in $2.7 \%$ of cases at our UK retrieval centre. The potential risk of a cold weld at revision surgery can be established using the implant design, interface materials and this problem can be partially solved with the use of appropriate equipment. The Biomet/Type 1 Taper design and the Ti-Ti interface material showed the greatest number of true clinical cold-welds and these were most likely as a result of corrosion at this interface. Currently, no patient or surgical factors can be used to 
261 predict clinical cold-welding. We found the JRI model separator to be superior at

262 separating apparently cold welded implants. To minimise the risk to the patient and

263 manage resources appropriately, we encourage surgeons to consider these factors

264 when planning revision surgery.

265

266

267

268

269

270

271

272

273

274

275

276

277

278

279 
282 1. Registry, N.J., National Joint Registry 11th Annual Report 2014. 2014.

283 2. Cooper, H.J., et al., Corrosion at the head-neck taper as a cause for adverse local tissue reactions after total hip arthroplasty. J Bone Joint Surg Am, 2012. 94(18): p. 1655-61.

3. Hussenbocus, S., et al., Head-neck taper corrosion in hip arthroplasty. Biomed Res Int, 2015. 2015: p. 758123.

4. Srinivasan, A., E. Jung, and B.R. Levine, Modularity of the femoral component in total hip arthroplasty. J Am Acad Orthop Surg, 2012. 20(4): p. 214-22.

5. Dyrkacz, R.M., et al., The influence of head size on corrosion and fretting behaviour at the head-neck interface of artificial hip joints. J Arthroplasty, 2013. 28(6): p. 1036-40.

6. Matthies, A.K., et al., Material Loss at the Taper Junction of Retrieved Large Head Metal-onMetal Total Hip Replacements. Journal of Orthopaedic Research, 2013. 31(11): p. 1677-1685.

7. Fraitzl, C.R., et al., Corrosion at the stem-sleeve interface of a modular titanium alloy femoral component as a reason for impaired disengagement. J Arthroplasty, 2011. 26(1): p. 113-9, 119 e1.

8. Grupp, T.M., et al., Modular titanium alloy neck adapter failures in hip replacement--failure mode analysis and influence of implant material. BMC Musculoskelet Disord, 2010. 11: p. 3.

9. Kop, A.M., C. Keogh, and E. Swarts, Proximal component modularity in THA--at what cost? An implant retrieval study. Clin Orthop Relat Res, 2012. 470(7): p. 1885-94.

10. Nassif, N.A., et al., Taper design affects failure of large-head metal-on-metal total hip replacements. Clin Orthop Relat Res, 2014. 472(2): p. 564-71.

11. Mokka, J., et al., Adverse reaction to metal debris after ReCap-M2A-Magnum large-diameterhead metal-on-metal total hip arthroplasty. Acta Orthop, 2013. 84(6): p. 549-54.

12. Goldberg, J.R., et al., A multicenter retrieval study of the taper interfaces of modular hip prostheses. Clin Orthop Relat Res, 2002(401): p. 149-61.

13. Langton, D.J., et al., Taper junction failure in large-diameter metal-on-metal bearings. Bone Joint Res, 2012. 1(4): p. 56-63.

14. Hexter, A., et al., MECHANISM OF CORROSION IN LARGE DIAMETER HEAD METAL-ON-METAL TOTAL HIP ARTHROPLASTY: A RETIREVAL ANALYSIS OF 161 COMPONENTS. Bone \& Joint Journal Orthopaedic Proceedings Supplement, 2013. 95-B(SUPP 12): p. 4.

15. Kocagöz, S.B., et al., Does taper angle clearance influence fretting and corrosion damage at the head-stem interface? A matched cohort retrieval study. Seminars in Arthroplasty, 2013. 24(4): p. 246-254.

16. Hothi, H.S., et al., Influence of stem type on material loss at the metal-on-metal pinnacle taper junction. Proceedings of the Institution of Mechanical Engineers Part H-Journal of Engineering in Medicine, 2015. 229(1): p. 91-97.

17. Hothi, H.S., et al., The reliability of a scoring system for corrosion and fretting, and its relationship to material loss of tapered, modular junctions of retrieved hip implants. J Arthroplasty, 2014. 29(6): p. 1313-7.

18. Walsh, C.P., et al., Revision of Recalled Modular Neck Rejuvenate and ABG Femoral Implants. J Arthroplasty, 2015. 30(5): p. 822-6.

19. Foote, J., et al., Length of stay following primary total hip replacement. Ann R Coll Surg Engl, 2009. 91(6): p. 500-4. 


\section{Acknowledgements}

We are grateful for the support of Gwynneth Lloyd, and Elizabeth Ellis for their coordination of the retrieval centre. Two authors received funding from the British Orthopaedic Association through an industry consortium of nine manufacturers: DePuy International Ltd (Leeds, UK), Zimmer GmbH (Winterthur, Switzerland), Smith \& Nephew UK Ltd (Warwick, UK), Biomet UK Ltd (Bridgend, South Wales, UK), JRI Ltd (London, UK), Finsbury Orthopaedics Ltd (Leatherhead, UK), Corin Group PLC (Cirencester, UK), Mathys Orthopaedics Ltd (Alton, UK), and Stryker UK Ltd (Newbury, UK). 
Table 1 - Demographic, Metal Ion Concentrations, Reason for Revision and Implant Information 


\section{ACCEPTED MANUSCRIPT}

Table 2 - Implant Design and Material Combinations

\begin{tabular}{llllll}
\hline Bearing Design & $\begin{array}{l}\text { Head } \\
\text { Material }\end{array}$ & $\begin{array}{l}\text { Taper Sleeve } \\
\text { Y/N }\end{array}$ & $\begin{array}{l}\text { Taper Sleeve } \\
\text { Material }\end{array}$ & $\begin{array}{l}\text { Stem } \\
\text { Material }\end{array}$ & Number \\
\hline Biomet M2a-Magnum & $\mathrm{CoCr}$ & $\mathrm{Y}$ & $\mathrm{Ti}$ & $\mathrm{Ti}$ & 13 \\
ASR & $\mathrm{CoCr}$ & $\mathrm{Y}$ & $\mathrm{CoCr}$ & $\mathrm{Ti}$ & 4 \\
Pinnacle & $\mathrm{CoCr}$ & $\mathrm{N}$ & $\mathrm{N} / \mathrm{A}$ & $\mathrm{Ti}$ & 2 \\
Cormet & $\mathrm{CoCr}$ & $\mathrm{N}$ & $\mathrm{N} / \mathrm{A}$ & $\mathrm{Ti}$ & 5 \\
Mitch & $\mathrm{CoCr}$ & $\mathrm{N}$ & $\mathrm{N} / \mathrm{A}$ & $\mathrm{SS}$ & 2 \\
Metasul & $\mathrm{CoCr}$ & $\mathrm{N}$ & $\mathrm{N} / \mathrm{A}$ & $\mathrm{SS}$ & 1 \\
\hline
\end{tabular}


Table 3 - Demographic, Metal Ion Concentrations, Reason for Revision and Implant Information for Components that were Successfully Separated after Disassembly Test

\begin{tabular}{|c|c|c|c|}
\hline & Number & Medians & Range \\
\hline $\begin{array}{l}\text { Gender (male:female) } \\
\text { Age at primary surgery (years) } \\
\text { Time to revision (months) } \\
\text { Femoral head diameter (mm) } \\
\text { Whole blood cobalt (ppb) } \\
\text { Whole blood chromium (ppb) }\end{array}$ & & $\begin{array}{c}55 \\
49.5 \\
44 \\
6.9 \\
3.38\end{array}$ & $\begin{array}{c}7: 4 \\
50-73 \\
25-96 \\
28-56 \\
0.60-20.41 \\
1.20-60.53\end{array}$ \\
\hline $\begin{array}{l}\text { Bearing design } \\
\text { Biomet M2A-Magnum } \\
\text { Stem Design } \\
\text { Biomet - Taperloc }\end{array}$ & 2 & & \\
\hline $\begin{array}{l}\text { Bearing design } \\
\text { ASR } \\
\text { Stem Design } \\
\text { Corial }\end{array}$ & $\begin{array}{l}2 \\
2\end{array}$ & & \\
\hline $\begin{array}{l}\text { Bearing design } \\
\text { Cormet } \\
\text { Stem Design } \\
\text { Zweymuller }\end{array}$ & 3 & & \\
\hline $\begin{array}{l}\text { Bearing design } \\
\text { Pinnacle } \\
\text { Stem Design } \\
\text { Corial } \\
\text { S-ROM }\end{array}$ & $\begin{array}{l}2 \\
1 \\
1\end{array}$ & & \\
\hline $\begin{array}{l}\text { Bearing design } \\
\text { Mitch } \\
\text { Stem Design } \\
\text { Exeter }\end{array}$ & $\begin{array}{l}1 \\
1\end{array}$ & & \\
\hline $\begin{array}{l}\text { Bearing design } \\
\text { Metasul } \\
\text { Stem Design } \\
\text { Sulzer Allo Pro }\end{array}$ & 1 & & \\
\hline $\begin{array}{l}\text { Reason for Revision } \\
\text { Aseptic Loosening (Femoral) } \\
\text { Fracture } \\
\text { Unexplained Pain } \\
\text { Gluteal Atrophy }\end{array}$ & $\begin{array}{l}8 \\
1 \\
1 \\
1\end{array}$ & & \\
\hline
\end{tabular}


Table 4 - Demographic, Metal Ion Concentrations, Reason for Revision and Implant Information for Components that were CCW after Disassembly Test

\begin{tabular}{|l|c|c|c|}
\hline & Number & Medians & Range \\
\hline Gender (male:female) & & & $5: 11$ \\
Age at primary surgery (years) & & 62.5 & $51-78$ \\
Time to revision (months) & & 62 & $29-131$ \\
Femoral head diameter (mm) & & 46 & $42-58$ \\
Whole blood cobalt (ppb) & & 7 & $1.07-97.53$ \\
Whole blood chromium (ppb) & & 10.19 & $0.71-31.46$ \\
\hline Bearing design & 11 & & \\
Biomet Magnum & & & \\
Stem Design & 9 & & \\
Biomet - Taperloc & 2 & & \\
Biomet - Bi-Metric & 2 & & \\
\hline Bearing design & 2 & & \\
ASR & & & \\
Stem Design & 2 & & \\
Corial & 1 & & \\
\hline Bearing design & 2 & & \\
Cormet & & & \\
Stem Design & & & \\
Zweymuller & 2 & & \\
\hline Bearing design & & & \\
Mitch & & & \\
Stem Design & & & \\
Exeter & & & \\
\hline Reason for Revision & & & \\
Unexplained Pain & & & \\
Aseptic Loosening (Femoral) \\
Aseptic Loosening (Acetabular) \\
Calcar Lysis & & & \\
Osteolysis & & & \\
\hline
\end{tabular}


Table 5 - Demographic, Metal Ion Concentrations, Reason for Revision and Implant Information for the group of retrieved implants that arrived with femoral head still attached to stem

\begin{tabular}{|l|c|c|c|}
\hline Cold-Welded & Yes & No & p-value \\
\hline Taper Type & Type 1 & Type 1 & - \\
\hline Head Taper Material & $\mathrm{Ti}$ & $\mathrm{Ti}$ & - \\
\hline Stem Trunnion Material & $\mathrm{Ti}$ & $\mathrm{Ti}$ & $\mathrm{p}=0.054$ \\
\hline Gender (Male : Female) & $3: 8$ & $12: 23$ & $\mathrm{p}=0.067$ \\
\hline Head Size (mm) & $48(44-58)$ & $46(36-58)$ & $\mathrm{p}=0.380$ \\
\hline Age at Primary Surgery (years) & $64.5(50-78)$ & $59(40-82)$ & $\mathrm{p}=0.687$ \\
\hline Time to Revision (months) & $53.5(28-95)$ & $49(12-149)$ & - \\
\hline Whole Blood Cobalt (ppb) & $8.16(0.6-97.53)$ & $4.23(0.6-212.4)$ & - \\
\hline Whole Blood Chromium (ppb) & $8.26(0.71-31.46)$ & $3.76(0.71-96.7)$ & \\
\hline Reason for Revision & & & \\
& & 22 & \\
Unexplained Pain & 8 & 2 & \\
Femoral Loosening & 1 & 4 & \\
Acetabular Loosening & 1 & 1 & \\
Osteolysis & 1 & 3 & \\
Impingement & 0 & 2 & \\
ARMD & 0 & 1 & \\
Acetabular Fracture & 0 & & \\
& & & \\
\hline
\end{tabular}


Figure 1: Study design

Figure 2: Image of the JRI head/neck separator

Figure 3: Graph showing the stress/strain during the mechanical disassembly test

Figure 4: (a) Photograph showing sectioned Biomet M2a-Magnum titanium taper sleeve with trunnion still engaged after CCW with red box highlighting the corrosion at the interface (b) microscopic image (x30) showing the corrosion products in the interface

Figure 5: (a) Pre-revision plain radiograph showed a well-fixed stem, (b) the retrieved implant ( $\mathrm{Ti}$ stem trunnion and Ti taper sleeve) were inseparable / "truly clinically cold-welded" after use of 5 types of head-neck separators, (c) Ti stem trunnion and Ti taper sleeve junction, (d) evidence of corrosion at this junction, (e) sectioned cold welded head showing corrosive debris on the taper and trunnion 


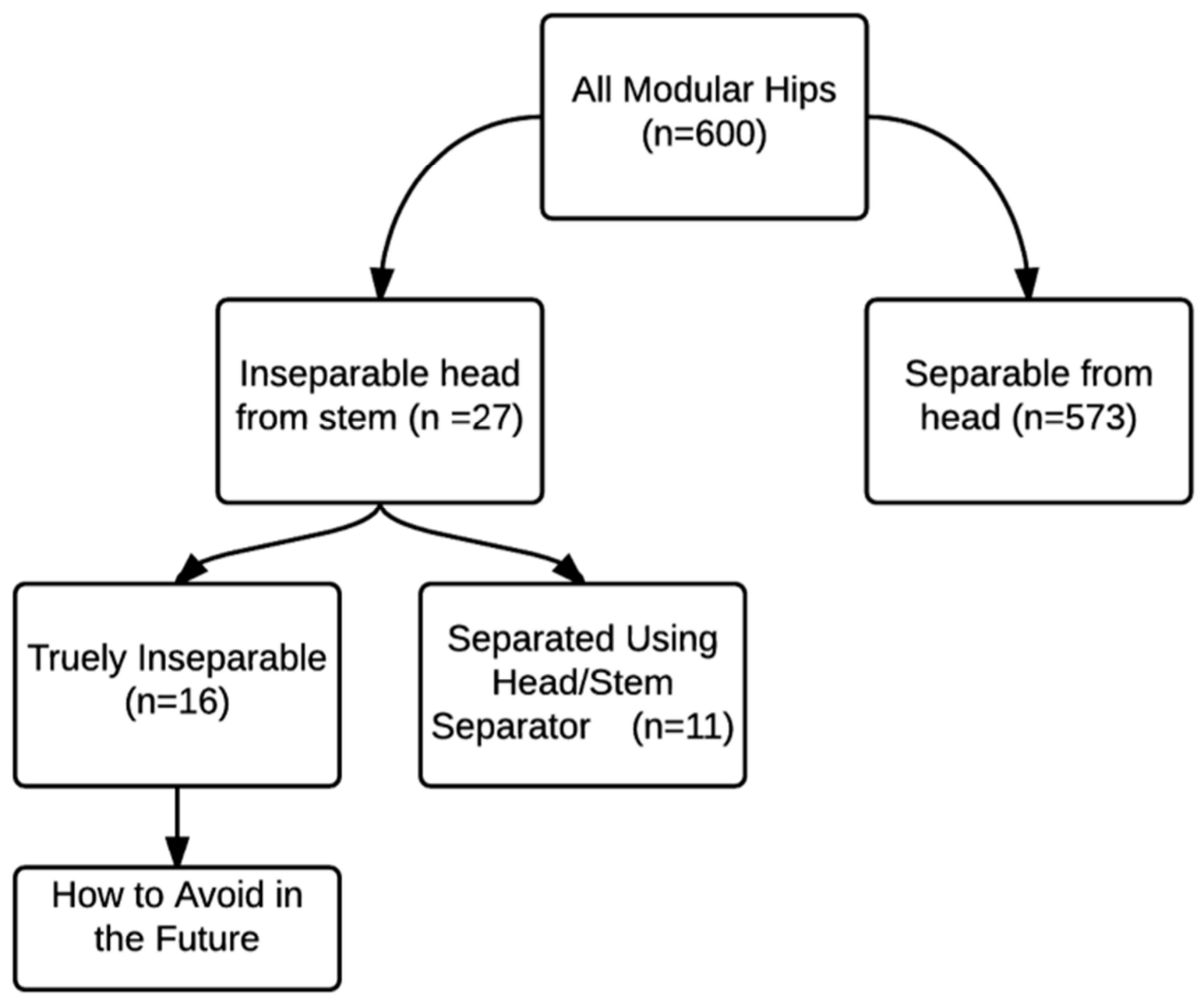




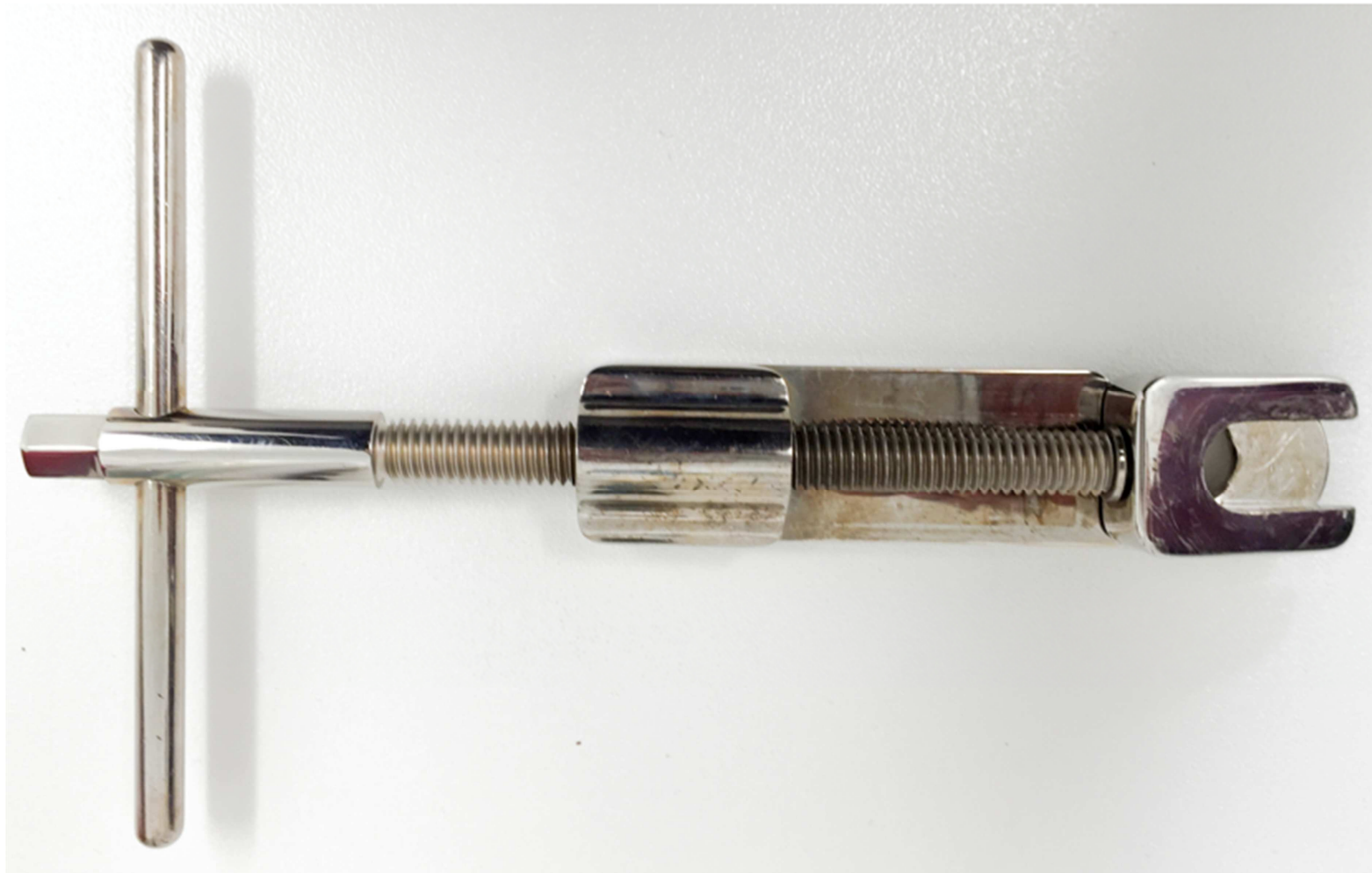




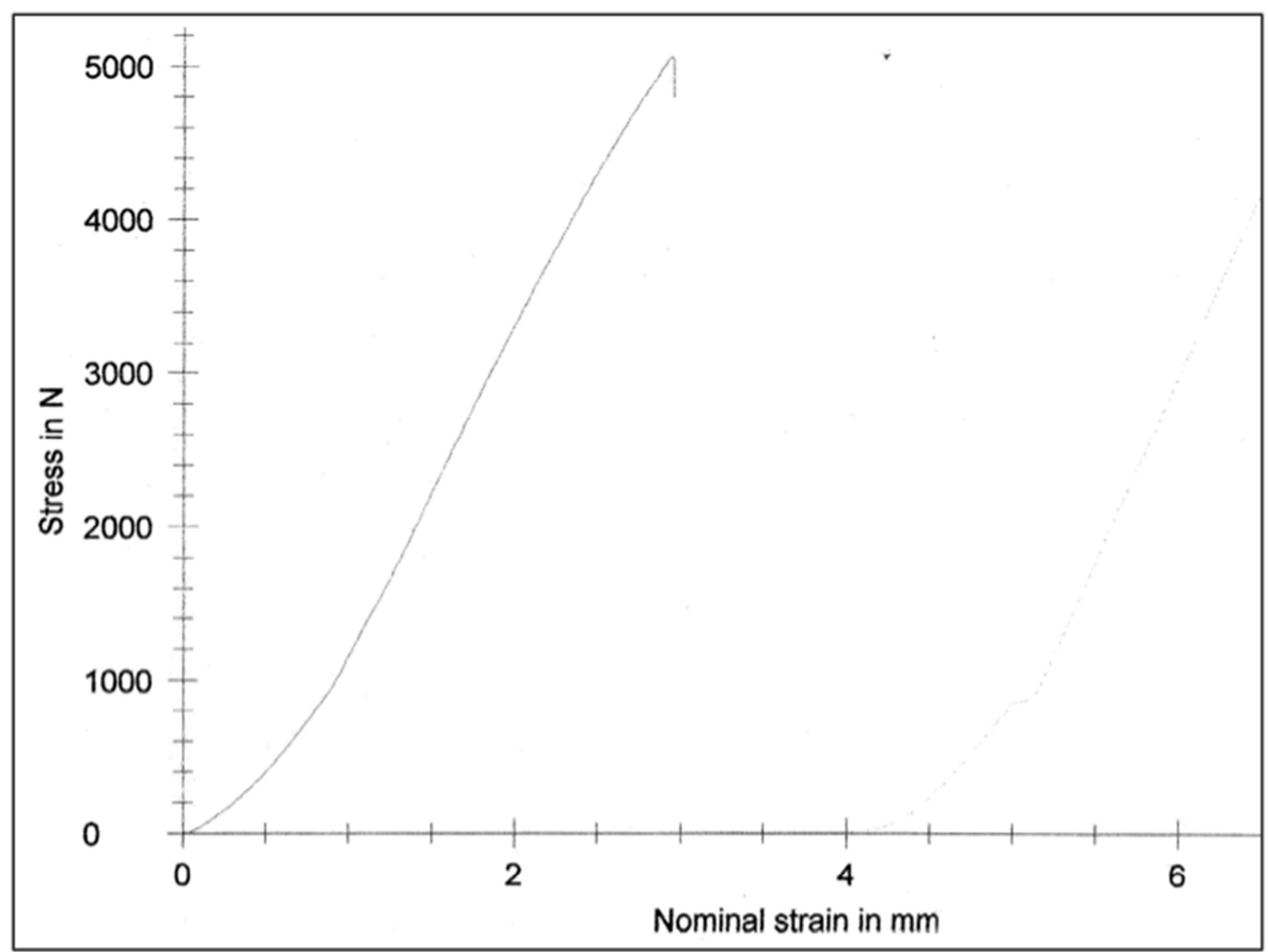



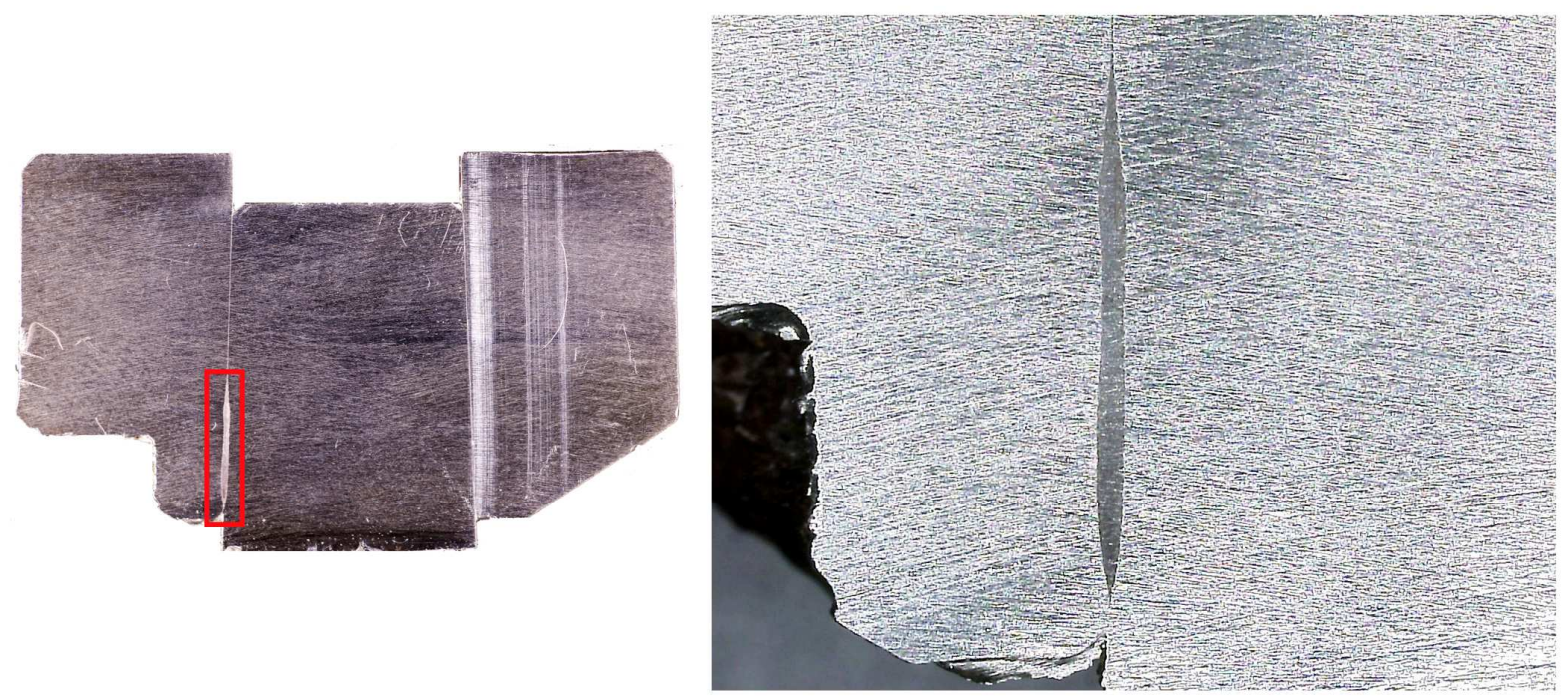

(a)

(b) 
(a)

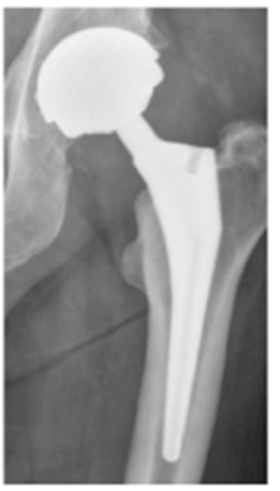

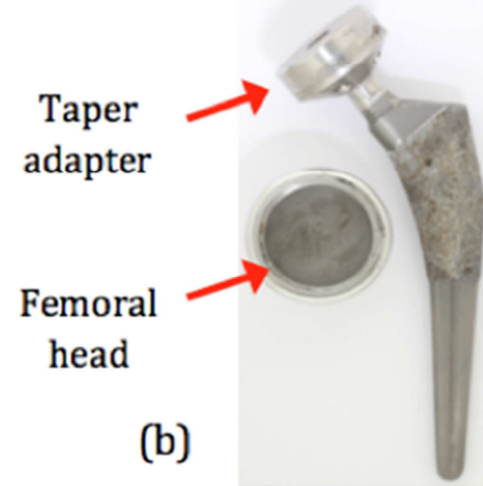

(b)
Ti-Ti taper junction

(c)

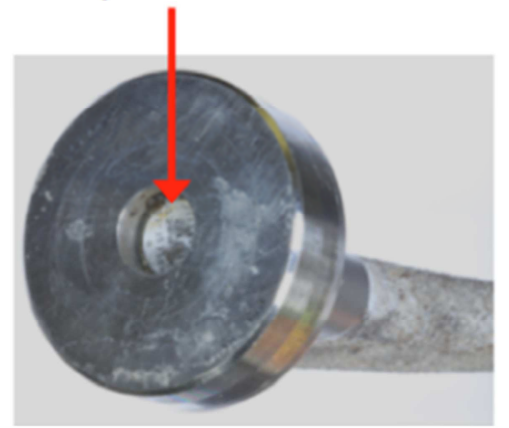

Corrosion at Ti-Ti taper junction

(d)

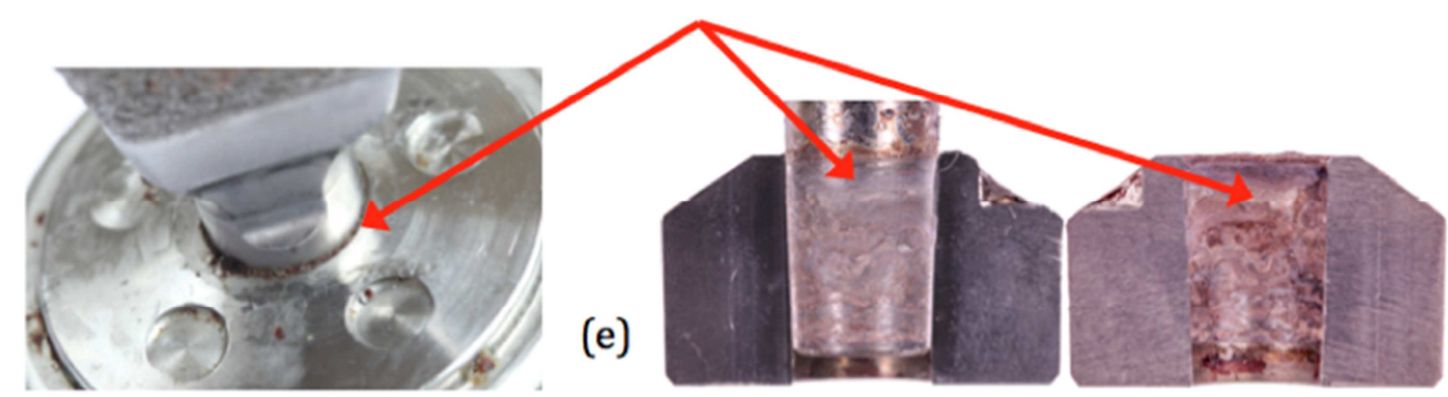

